\title{
Practical Teaching Research of Data Science and Big Data Technology Major Under Engineering Education Background
}

\author{
Le Wei*, Qiuyun Zhao \\ School of Software Engineering, Chengdu University of Information Technology, Chengdu 610225, China \\ *Corresponding author. Email: weile@cuit.edu.cn
}

\begin{abstract}
It is an important measure to make up for the talent gap of big data industry in China to set up data science and big data technology majors in Colleges and universities. Practice teaching plays an irreplaceable role in the cultivation of big data talents. Taking the practical teaching of data science and big data technology in Chengdu University of Information Technology as the research object, research is also combined with the requirements of CDIO engineering education. From two aspects: the construction of a professional practice curriculum system and the reform of project-driven practical teaching model, we discuss the project-driven big data professional practical teaching. It is characterized by the design of reasonable engineering projects, decomposed by 'modular' according to the curriculum system. The whole project is dispersed in the practice course, and students' mastery of knowledge is realized through 'project-driven, learning by doing", so as to improve students' practical ability, practical innovation and entrepreneurship ability, and team cooperation ability, and finally achieve goals of professional training.
\end{abstract}

Keywords: Engineering education, big data, practical teaching, project-driven, project case

\section{INTRODUCTION}

Because of the huge commercial value contained in big data, big data has become a hot spot in the field of information and communication technology and a new direction of industrial development and has received extensive attention from academia and industry. In the 'Outline of Action for the Promotion of Big Data Development' and the 'Big Data Industry Development Plan (2016-2020)', the state clearly points out that it is necessary to 'strengthen the innovation and development ability of big data industry, comprehensively improve the resource control ability, technical supportability and value mining ability of big data in China, and accelerate the construction of a data power'. It is also proposed to 'strengthen the training of big data talents, encourage universities to explore the establishment of a mechanism to train professional talents and cross-border composite talents in the field of big data, and strengthen the cultivation of professional practice skills for big data talents.'

Since 3 colleges and universities opened data science and big data technology majors in 2016, 617 colleges and universities in China have opened data science and big data technology majors, it is hoped to cultivate compound big data talents with the outstanding practical ability and technological innovation ability through higher education. Society needs scientists and engineers with big data processing ability[1], that is to say, they need to have solid mathematical basic knowledge and innovation ability, master the basic theory, method, and technology-based on data analysis, and be able to engage in the design and development of software system for big data service, data analysis, and management. They should be compound, high-quality and application-oriented talents in data science and big data engineering. Combining with the shortage of big data positions[2] needs of enterprises (ETL developers, Hadoop developers, visualization tool developers, data scientists, OLP developers, data warehouse equipment experts, predictive analysis developers, and information architects), it can be seen that, Having engineering application ability is a typical characteristic of big data talents.

CDIO higher engineering education takes the whole process of 'conception design implementation operation' as the carrier to cultivate students' engineering ability[3], by advocating the new teaching model of 'learning by doing' and 'based on project education and learning', it focuses on training students' engineering basic knowledge, personal ability, interpersonal team ability, and engineering system ability, and cultivates engineers with engineering professional ability, social consciousness, entrepreneurship, and innovation spirit to meet the needs of modern social talents.[4]Project-driven teaching is a new type of teaching method based on the theory of constructivism. It is in line with the 'life cycle of product development to product operation' as the carrier emphasized by CDIO engineering education. Let students 'learn engineering in an active, practical, and organic way between courses' and 'the ability of engineering graduates is divided into four levels of engineering basic knowledge, personal ability, interpersonal team ability, and 
engineering system ability' fit naturally. Therefore, it is of great significance to introduce project-driven into the teaching of big data science and technology professional courses and to specially add engineering practice courses to realize the cultivation of big data talents' engineering application ability through project-driven teaching methods.

This article takes the construction of the data science and big data technology major of the Chengdu University of Information Technology as an example, from the three aspects of practical curriculum system construction, practical teaching project design, and practical teaching mode reform, it explains how local colleges and universities carry out project-driven data science and big data technology professional practice teaching in the context of engineering education to establish a professional talent training system, ensure the quality of talent training, and serve local and national economic construction.

\section{DATA SCIENCE AND BIG DATA TECHNOLOGY PROFESSIONAL PRACTICE COURSE SYSTEM CONSTRUCTION}

The major of data science and big data technology emphasizes the different knowledge system intersections and the cultivation of students' practical ability. Therefore, in the construction of the curriculum system, it is necessary to consolidate the students' basic knowledge of disciplines, but also to reflect the interdisciplinary, and at the same time strengthen the students' practical ability and teamwork ability [5]. Taking into account the actual situation of the Chengdu University of Information Technology, combined with the practice of early engineering education, engineering application characteristics are considered deeply in the design of the curriculum system. The entire professional curriculum is divided into general education courses, subject basic courses, and professional courses. These courses involve mathematics, computer, and statistics related content. From the perspective of practical teaching, these courses cover practical teaching links such as experiment, comprehensive practice, and internship training, as shown in Table 1. Main goals and courses involved in each link are as follows:

Table 1 Data science and big data technology professional practice course system

\begin{tabular}{|l|l|}
\hline Practical teaching links & \multicolumn{1}{|c}{ Course } \\
\hline \multirow{5}{*}{ Experiment } & C Language Programming \\
\cline { 2 - 3 } & Data Structure \\
\cline { 2 - 3 } & Object-Oriented Programming(Java) \\
\cline { 2 - 3 } & Principles of Computer Organization \\
\cline { 2 - 3 } & Data Mining and Analysis \\
\cline { 2 - 3 } & Python Programming \\
\cline { 2 - 3 } & Fundamental of Information Retrieval \\
\cline { 2 - 3 } & Engineering Practice on Mathematical Methods \\
\cline { 2 - 3 } & Big Data Systems and Technologies \\
\cline { 2 - 3 } & Textual Data Mining \\
\cline { 2 - 3 } & Natural Language Processing \\
\cline { 2 - 3 } & Intelligent Text Analysis \\
\cline { 2 - 3 } & Image Processing Techniques \\
\cline { 2 - 3 } & Image Analysis Methods \\
\cline { 2 - 3 } & Deep Learning Algorithms and Practice \\
\hline
\end{tabular}




\begin{tabular}{|l|l|}
\hline Practical teaching links & \multicolumn{1}{|c|}{ Course } \\
\hline \multirow{5}{*}{ Engineering practice } & Web Application Programming(Java) \\
\cline { 2 - 2 } & Application Technology of Database(MySQL) \\
\cline { 2 - 2 } & Fundamental of Data Visualization \\
\cline { 2 - 2 } & Big Data Machine Learning \\
\cline { 2 - 2 } & Theory and Application of Algorithm Analysis(independent courses) \\
\hline \multirow{5}{*}{ Internship training } & Engineering Practice 1 (Coding Training) \\
\cline { 2 - 2 } & Engineering Practice on Big Data 1 \& Engineering Practice on Big Data 2 \\
\hline & Team Motivation and Communication \\
\cline { 2 - 2 } & Professional Practice of Software Engineering \\
\cline { 2 - 2 } & Graduation Practice \\
\cline { 2 - 2 } & Graduation Thesis/Design \\
\hline
\end{tabular}

(i) Experiment

Curriculum experiment is an important link of the combination between theory and practice. Its purpose is to help students understand and master theoretical knowledge, and cultivate students' innovative and practical abilities. Experimental courses include in-class experiments and independent experimental courses. Inclass experiments are set up with theoretical courses, it mainly includes C Language Programming, Data Structure, Object-Oriented Programming (Java), Database Principles and Applications, Principles of Computer Composition, Data Mining and Analysis,etc. These cover basic mathematics and science, basic subject courses, and professional courses. The independent experimental course is Algorithm Analysis Theory and Application. The purpose of this course is to cultivate students' computer thinking, help students integrate the knowledge they have learned, build a complete coding knowledge system, and improve students' ability to abstract modelling of practical problems.

(ii) Engineering practice

Engineering practice is the basic way to implement engineering education, and it is a very important and indispensable part of engineering education. The purpose of setting up engineering practice courses is to enhance students' in-depth understanding of the knowledge and professional skills learned, consolidate the theoretical knowledge learned, master professional skills, cultivate students' independent and cooperative work abilities, make students develop in three aspects: knowledge, ability, and emotional attitude. Combining professional characteristics and traditional advantages, four courses are mainly set up: Engineering Practice 1 (Coding Training), Engineering Practice 2 (Software Technology), Big Data Engineering Practice 1 and Big Data Engineering Practice
2.Engineering Practice 1 and Engineering Practice 2 are from the perspective of software development, enabling students to understand and master the core software engineering basic knowledge and principles of software design engineering, software manufacturing engineering, software testing, and quality assurance. These practice courses also make students work in demand, design, development, testing, maintenance, and other positions in the software team, master the basic methods of document retrieval and data query, and train students to obtain information and solve problems, to understand the methods and strategies of interpersonal communication, and be able to communicate in writing, multimedia, diagrams, and have certain oral expression skills.

Big Data Engineering Practice 1 and Big Data Engineering Practice 2 are from the perspective of big data applications, enable students to use big data-related methods and technologies to conceive, design, implement and implement corresponding software service systems according to the needs of specific industries, and use big data to solve specific industry application problems. The two courses cultivate students' innovative ability, good communication skills, and certain project management skills.

(iii) Internship training

Internship training is an important teaching link for training students to analyze and solve problems, acquire knowledge, and use knowledge to innovate. It is also an important teaching link for practicing engineering education concepts. The data science and big data technology professional internship training links in Chengdu University of Information Technology mainly include Team Motivation and Communication, Software Engineering Professional Practice, Graduation Practice and Graduation Thesis (Design). Among them: 
The purpose of Team Motivation and Communication is to enable students to master and understand the methods and methods of team building coordination and communication. Training students' teamwork and communication skills through team building, team charter establishment, teamwork projects, technical documents, team project summary report compilation, cultivate students' ability to lead and collaborate in the future work process.

Software Engineering Career Practice takes software engineering projects as the carrier. This course helps students master the knowledge necessary to engage in related occupations through the relationship between software engineering activities and the environment and sustainable development, software engineer professional standards, effective communication with project stakeholders, effective project management, and lifelong learning to adapt to career development, etc. It lays a solid foundation for social work.

The purpose of Graduation Internship is to let students understand the culture and system of the company, and be familiar with the work process and working methods of the company, comprehensively use the professional knowledge and skills learned to analyze and solve practical problems. This link aims to deepen students' theoretical understanding, expand knowledge fields, and extend professional skills.

The purpose of the Graduation Thesis (Design) is to allow students to link the knowledge they have learned during the university to solving practical problems. Cultivate students to independently apply the basic theories, professional knowledge, and basic skills they have learned. This process could improve students' ability to analyze and solve practical problems, and make them able to independently solve complex engineering problems in data science. It would also cultivate students' self-study ability, communication ability, innovation ability, writing ability, and other comprehensive abilities, so that students would receive a good and systematic exercise in thinking style, learning perseverance, and work style.

\section{PROJECT-DRIVEN DATA SCIENCE AND BIG DATA TECHNOLOGY PROFESSIONAL PRACTICE TEACHING MODEL REFORM}

\subsection{Design Project Cases that Meet Application Requirements}

The project-driven practice teaching model takes the cultivation of engineering practice ability as the mainline, takes students as the center, and fully mobilizes students' subjective initiative [6]. This model requires that under the guidance of teachers, the teaching is carried out with project cases as a foreshadowing so that students can understand the goals and contents of practice. 'Learning by doing' is then done. Project cases are the foundation and key to realizing project-driven practical teaching. The original intention of big data technology development is to meet industry application needs, that is, it has applicationdriven characteristics. Therefore, it is necessary to actively carry out school-enterprise cooperation, and design project cases that meet application needs and professional training goals.

The design of the project case should focus on professional training objectives. On the one hand, it can be combined with the school's industry characteristics or advantages. For example, Chengdu University of Information Technology combines the background of the meteorological industry to design meteorological big data application cases in the project. Data collection, processing, storage, mining and analysis, visual display and other links; on the other hand, teachers can discuss with the cooperative enterprise and use the actual project of the enterprise as a teaching case. In addition, teachers can also use the teacher's scientific research project and some competition projects as a teaching case to achieve similar goals. The core of big data technology lies in data. When designing a project case, we must ensure that there is a basic condition of 'big data', otherwise the project will not have the characteristics of big data.

\section{2 'Modular' Decomposition of Project cases}

A big data project is a complex project, and it is impossible to complete such a project in one course. Therefore, it is necessary to carefully sort out the designed project cases to form a source project library. In accordance with the practical curriculum system of 'experiment-engineering practice-internship training', combined with the course objectives, the project cases are carried out according to the granularity of comprehensive design experiments, engineering design experiments, internships, practical training, curriculum design, and graduation design. With decomposition at different stages and levels, these engineering projects are from simple to complex, from part to whole, from cognition to design, from design to practice, from practice to implementation, step by step, making it possible to 'learn from projects'

\subsection{Project-driven Teaching Methods of Data Science and Big Data Technology Professional Practical Courses}

The project-driven data science and big data technology professional practice teaching model combine inside and outside the school, theory and practice, ability and ethics, and cultivates big data engineering application talents, big data technology talents, and big data compound talents. Pay attention to the following points in teaching:

(i) Carrying out practical teaching by a team

According to the principle of voluntary combination, students are divided into several groups, and the number of 
each group can be divided according to different course practice tasks. Several small projects that have been 'modularly' decomposed are completely handed over to each group to complete. The teacher only plays a role in guiding the direction of practice in the practice process, and only gives the practical results that students need to achieve at the end, and does not provide fixed practice steps and fixed the practice plan and fixed practice effects fully mobilize the enthusiasm of students, allowing students to integrate what they have learned to use their creativity and imagination to finally complete the practice. During the development of teamwork, teachers require students to reasonably allocate the human and material resources of the team themselves, learn how to communicate with members of this group and other groups during project implementation, experience the operation methods of actual engineering projects, and establish the spirit of teamwork.

(ii) The design of teaching link

In order to ensure the smooth progress of the course and overcome the laziness of the students, the teacher divides the course implementation into several links and sets stage results in each link. On the one hand, the assessment of phased results is used to monitor the progress of students' work, and on the other hand, it is also convenient to implement process assessment. Different practical courses have different teaching hours and course goals, so there will be differences in link design. For example, Big Data Engineering Practice 1 divides the implementation process into project requirements analysis, project plan analysis, project realization, project summary, and project demonstration according to the course objectives. It cultivates students' independent learning ability, ability to research, analyze and solve complex engineering problems, project management, and teamwork ability with analysis reports, design plans, summary reports, and systems Code and other achievements.

(iii) Reasonable design of teaching quality evaluation

The evaluation of practical courses (especially the courses offered independently) adopts a process-based evaluation method, taking engineering research ability, professional practice ability, and innovation ability as important evaluation criteria. The courses offered in the school are mainly evaluated from the aspects of intuitiveness, presentation, functionality, use-value orientation, workflow orientation, social acceptance, creativity, learning ability and effect, teamwork ability, etc.[7]. For corporate practice courses, the evaluation is mainly based on attendance, results, expression, ability, and development ability.

\section{CONCLUSION}

The purpose of the data science and big data technology major is to train high-level big data talents with big data thinking, using big data thinking and analytical application technology. Application-driven and demand-driven are the important characteristics of this major. This article explains how to construct a practical curriculum system rationally under the background of engineering education, and gives a plan for project design, project decomposition, and teaching implementation. As a newly opened major, many aspects of practical teaching are being explored, and there is no successful experience to learn from. This requires colleges and universities to combine their own reality and constantly explore and sum up for continuous improving.

\section{ACKNOWLEDGMENT}

This work was supported by the Education Research and Reform Project of Chengdu University of Information Technology (JY2018054).

\section{REFERENCES}

[1] J. Huang. Thinking and exploration on big data talent training, Education Teaching Forum, pp. 201-203, 2014.

[2] C. H. Feng, B. E. Guo, G. Liang. Discussion on the cultivation of innovation and entrepreneurship big data talents in Local Universities, Journal of XingTai University, vol. 32, pp. 148-150, 2017.

[3] F. E. Zhang, J. F. Xue, D. L. Li, et al. Research of cultivating mode of CDIO engineering talents, Experimental Technology and Management, vol. 27, pp. 810,2010

[4] J. R. Liu, M. H. Wu, Z. P. Li. Application of CDIO concept in computer hardware practice teaching reform, Experimental Technology and Management, vol. 28, pp. 154-156, 2011.

[5] D. L. Li, W. LV, Y. C. Liang. Research on the training model of big data talents based on Joint school-enterprise education, Software Guide, vol. 19, pp. 164-167, 2020.

[6] Z. Q. Zhou, S. P. Li, H. L. LV. Research on the construction of practical teaching system of Internet of things Engineering Specialty Based on project driven, Teaching Forum, pp. 129-130, 2015.

[7] H. H. Jiang, L. Ge, C. Wang. Exploration on practical teaching of data science and big data technology specialty based on OBE concept, think tank era, pp. 288+290, 2019. 